\title{
CONTRIBUIÇÕES DA PSICOLOGIA PARA O ESPORTE ENTREVISTA COM RUTH PAULS
}

\author{
Contributions from the Psychology field to the sport \\ Interview with Ruth Pauls
}

por Mariane Camargo de Mesquita ${ }^{1}$

Melina Gomes Madureira²

Graduada em Psicologia pela Universidade Tuiuti do Paraná em 1994, Ruth Pauls coordena o Centro Integrado da Psicologia do Esporte e das Ciências do Movimento Humano - CIPECIM, em Curitiba, que é resultado de muita experiência e estudo na área. Com pós-graduação em Psicologia do Exercício do Esporte no Centro Universitário FEEVALE (Novo Hamburgo, RS), mestrado em Ciências Aplicadas à Atividade Física e ao Esporte pela Universidade de Córdoba, na Espanha, a entrevistada atualmente está desenvolvendo seu doutorado nessa mesma universidade. Pauls atua também como psicóloga da Seleção Brasileira de Ginástica Olímpica e faz acompanhamento individual com diversos atletas. Na entrevista, ela expõe um pouco de sua experiência nesta área emergente da psicologia e comenta sobre as dificuldades encontradas, assim como o grande potencial de desenvolvimento que a Psicologia do Esporte oferece.

Pergunta: Fale sobre o CIPECIM e como ele surgiu?

Resposta: Em 2001, foi reaberto o Departamento Médico da Universidade do Esporte e a nutricionista Lili Purim Niehues retomou os trabalhos no Departamento da Psicologia em que eu atuava. Além de estruturar o Departamento, também foram realizados inicialmente concursos de Estágio teórico-prático de ambas as áreas (para os alunos de Nutrição e de Psicologia) das Universidades de Curitiba. Em novembro desse mesmo ano começamos o primeiro estágio em Psicologia Esportiva. Os trabalhos práticos foram realizados na própria Universidade do Esporte com equipes de vôlei feminino e com a equipe da seleção brasileira de ginástica olímpica. Em 2002 foram realizados mais dois concursos e assim fomos envolvendo cada vez mais alunos interessados em conhecer esta área. No fim daquele ano, 3 alunos terminaram o primeiro estágio e se formaram no curso de extensão da Psicologia Esportiva, reconhecida naquele momento pela Universidade Tuiuti do Paraná. Em 2003 e 2004 foram realizados mais concursos e novos alunos começaram a participar do estágio. Em 2003

1 Acadêmica do sexto período de Psicologia da PUCPR e bolsista da revista Psicologia Argumento.

2 Acadêmica do sexto período de Psicologia da PUCPR e estagiária do CIPECIM.

Endereço para contato: Av. Visconde de Guarapuava, 4487, ap 15. Curitiba-PR. 80240-010

E-mail: mariane.mesquita@pucpr.br 
quando a Universidade do Esporte recebeu o nome de Centro de Capacitação Esportiva e mudou de administração, também nasceu o Centro Integrado da Psicologia do Esporte e das Ciências do Movimento Humano. O Centro respondia, na época, também a uma necessidade de termos um órgão oficial dentro do Centro de Capacitação Esportiva que se propusesse a atender outros grupos esportivos, como alunos de academias de ginástica, alunos de academia de tênis e equipes esportivas dentro de colégios do ensino médio. No fim de 2004 quinze estagiários haviam terminado o Curso teórico-prático do CIPECIM. Em 2005 o grupo foi composto por 24 pessoas, entre elas estagiários, profissionais, residentes; todos trabalhando em diversas atividades esportivas, tanto com esportes coletivos como individuais, acompanhamento esportivo a atletas e pesquisas em diversas áreas esportivas. Hoje, o CIPECIM fornece um curso teórico-prático em Psicologia Esportiva com duração de 1 ano. É possível permanecer no curso, após 1 ano, tornando-se residente do CIPECIM. Na parte prática são desenvolvidas atividades com atletas, equipes e treinadores, visando ao aproveitamento máximo do potencial psicológico do atleta. Na parte teórica, as atividades práticas são avaliadas e planejadas.

Pergunta: Como você vê a psicologia do esporte, de que forma e onde ela atua?

Resposta: A psicologia do esporte é uma área emergente. Na verdade no Brasil ela já tem uns 50 anos. Mas mesmo assim como ela não faz parte das grades curriculares, muitos alunos nunca ouviram falar da psicologia do esporte. Então a psicologia aplicada ao esporte, acho que podemos falar melhor assim, pode trabalhar tanto na educação do atleta quanto no acompanhamento desse atleta ou de uma pessoa que realiza a atividade física ou das crianças que podem ser despertadas para o esporte de rendimento. Ela atua em todos os campos em que o esporte e a atividade física estão presentes, desde escolas até os clubes, confederações, federações, às academias que estão aos poucos dando abertura para este tipo de trabalho. É um campo de trabalho imenso e a psicologia precisa ser despertada para esta área de trabalho.
Pergunta: Como você começou a trabalhar com o esporte?

Resposta: Há quase nove anos. Eu comecei atuando com uma nutricionista que na mesma época trabalhava com atletas, que começaram a solicitar um trabalho com a psicologia. Assim, eu comecei com uma turma de atletismo no Paraná Clube. Acompanhei este grupo por um ano e isso me despertou novos interesses, pois percebi que os fundamentos da psicologia geral e da psicologia do esporte poderiam ser aplicados e adaptados. E, nesse sentido, comecei a procurar por outras literaturas, mas achei muito pouco. Foi então que busquei novos cursos. O primeiro curso que eu fiz foi na PUCPR. Depois fui para fora, sempre buscando mais informação. O primeiro congresso da área que eu participei só foi em 2000, quatro anos depois do início do meu trabalho. Desde o início esse trabalho me empolgou muito, porque é um campo que ainda não está sendo explorado. Então, desde o início me despertou muito interesse.

Pergunta: Como foi seu trabalho com a equipe de Ginástica Olímpica? Comente sobre essa experiência.

Resposta: Bom, na ginástica olímpica eu trabalhei 4 anos diretamente com a equipe da seleção. E continuei atendendo, acompanhando as atletas individualmente. E também com as meninas mais novas que não estão na seleção, mas que estão treinando para qualquer momento entrar na equipe. O trabalho na ginástica foi muito rico durante os 4 anos, pois foi nesse período que as preparei para as olimpíadas, tanto a de Sidney quanto a de Atenas. Na época das Olimpíadas de Sidney elas ainda não estavam permanentemente instaladas aqui em Curitiba, então vinham de tempos em tempos para o acompanhamento. Somente dois anos depois deste período é que elas vieram para integrar uma equipe permanente aqui em Curitiba. E foi um trabalho muito gostoso. Sempre junto com os técnicos, com a coordenação e a equipe médica. Ou seja, foi um trabalho multidisciplinar. Continuo em contato com eles. No momento não ocorre um trabalho de grupo, mas acredito que todo o tempo que foi feito este trabalho foi de grande importância. O trabalho foi sempre focado na consciência corporal e na ansiedade que o próprio esporte traz. 
Pergunta: Tendo em vista que é um trabalho multidisciplinar, como você define a relação do psicólogo com o educador físico?

Resposta: $O$ professor de educação física, o técnico ou preparador físico são os principais profissionais com quem trabalhamos no esporte. Então, eu acredito que a relação tem que ser a melhor possível. Desde o início, devemos mostrar que nós estamos ali no campo deles, para ajudar e fazer uma parceria de trabalho. Temos que mostrar que caminhando juntos podemos ajudá-los em muitas coisas. Nós nunca vamos substituí-los, nunca vamos fazer a parte deles, como eles também não irão fazer a nossa. Então, quando este profissional percebe o quanto o psicólogo pode caminhar com ele, como pode ajudá-lo, geralmente tem mais abertura para a parceria. Poucas vezes, nesses nove anos, eu não consegui essa abertura. E aí se forma aquele trabalho interdisciplinar o qual é importante irmos ampliando cada vez mais para as diversas áreas. $\mathrm{Na}$ questão do esporte, essa parceria é com o educador físico e o técnico e essa relação tem que ser de parceria mesmo, cada um fazendo a sua parte com o atleta ou com o grupo quando existe necessidade.

Pergunta: Como é a pesquisa na psicologia do esporte?

Resposta: Para mim a pesquisa é fundamental. Todo nosso trabalho prático tem que ter fundamentação teórica. Eu sempre pesquisei e vejo que, quando faço uma pesquisa, muitas vezes ela começa a comprovar aquilo que já estudei na teoria. Ou seja, você fundamenta seu trabalho e ao mesmo tempo comprova-o. Outras vezes, questões se levantam na prática e eu vou buscando uma explicação, uma compreensão maior. Para mim, em qualquer área de atuação, a pesquisa faz parte e nos dá fundamentação para o trabalho.

Pergunta: Como está o mercado de trabalho para o psicólogo do esporte?

Resposta: Ele está se abrindo. Vejo que o trabalho da psicologia do esporte auxilia a melhoria de outros trabalhos, como o dos técnicos e do educador físico. Para maior abertura, basta que o psicólogo se posicione de forma firme, mostrando o seu trabalho e a importância de estar trabalhando também o aspecto psicológico do atleta. Acredito que isto está em franca expansão. A princípio, é necessário procurar as pessoas e os lugares certos para trabalhar, mostrar o que pode ser feito e depois vender o nosso trabalho.

Pergunta: Quais os requisitos que o psicólogo que está começando na área deve ter?

Resposta: Ele precisa de formação, porque não é saindo de uma graduação de psicologia que ele estará preparado. As universidades não têm essa área na grade curricular, sendo assim, elas acabam preparando para outras áreas, mas não para esta especificamente. A formação pode ser por uma pós-graduação, cursos teóricos e até mesmo do estágio. Espero que logo tenhamos aqui em Curitiba uma pós-graduação, um mestrado mais específico para essa formação. Mesmo porque o atleta não é um paciente, nós não fazemos terapia com ele. É diferente, nós fazemos o acompanhamento das necessidades que ele tem no esporte.

Pergunta: Você poderia citar exemplos de como é feito o trabalho da psicologia do esporte?

Resposta: A minha ênfase tem sido bastante no esporte individual. Então darei alguns exemplos de atletas individuais em que a intervenção e o acompanhamento psicológico foram muito importantes: o primeiro caso é de um atleta de natação que começou a se destacar positivamente e de forma significativa na equipe, mas sentiu-se isolado e já nem comemorava mais suas vitórias. Por isso procurou a psicologia e fizemos um trabalho de grupo com a equipe para haver novamente um entrosamento entre todos, além de termos trabalhado com ele individualmente para que compreendesse o que estava acontecendo. Esse trabalho foi desenvolvido em cerca de 6 meses. Outro caso é quando acontecem lesões. Na ginástica olímpica isso é muito freqüente. Em 2003, antes do Pan-americano, uma atleta que havia sido selecionada para o campeonato quebrou o braço em uma queda. Era notável sua tristeza ao ver as outras atletas fazendo as malas, ganhando seu material olímpico e ela não podendo ir junto. Nessa situação foi feito um trabalho individual, procurando ajudá-la a aceitar aquela situação. Ela não precisava aprovar e sim aceitar que teria outra chance. 
Em geral, esse é um momento em que há uma tendência forte para a depressão. Assim como esses, temos muitos outros exemplos em grupos também. A coesão é muito importante de ser trabalhada quando existe um indivíduo isolado do grupo e também o respeito diante de um técnico. São exemplos em que a psicologia pode intervir de maneira muito eficaz e trazer resultados melhores do que poderia ser esperado.
Pergunta: Como você vê a psicologia do esporte daqui a 10 anos?

Resposta: Espero que, com as universidades abrindo para a área do esporte como uma disciplina regular, mais alunos se interessarão pela área e conseqüentemente o mercado se abre, pois as pessoas estarão mais preparadas. Penso que em 10 anos nós podemos ter evoluído muito nesta área e espero que o psicólogo do esporte tenha um lugar muito seguro dentro do meio esportivo de qualquer instituição. 